\title{
First record of gorgeous swallowtail Meganthias natalensis, an anthiine fish (Acanthopterygii: Serranidae: Anthiinae) from Kenyan waters
}

\author{
MATTHIAS SCHNEIDER ${ }^{1,2}$ AND MICHAEL JANKE ${ }^{3}$ \\ ${ }^{1}$ HYDRA Institute for Marine Sciences, Elba Field Station, Loc. Fetovaia, Via del Forno 80, I-57034 Campo nell'Elba (LI), Italy, \\ ${ }^{2}$ Senckenberg Research Institute and Natural History Museum, Ichthyology section, Senckenberganlage 25, D-60325 Frankfurt am \\ Main, Germany, ${ }^{3}$ Alfred Wegener Institute for Polar and Marine Research, Biologische Anstalt Helgoland, Marine Station, Box 180, \\ D-27483 Helgoland, Germany
}

\begin{abstract}
Records of the anthiine fish genus Meganthias are rare and most species are only known from few specimens. On 17 February 2012 a specimen of Meganthias natalensis, $\sim 400 \mathrm{~mm}$ standard length was caught in $150 \mathrm{~m}$ depth about 10 nautical miles off Watamu, Kenya. This is the first record of the species from Kenyan waters.
\end{abstract}

Keywords: rare, deep-water, anthiine, gorgeous swallowtail, Meganthias natalensis, Kenya, Western Indian Ocean

Submitted 26 February 2012; accepted 14 December 2012

\section{INTRDDUCTIDN}

More than 475 valid species, living in temperate and tropical seas worldwide, have been placed in the perciform family Serranidae (Nelson, 2006). To date, one of three widely accepted serranid subfamilies, the Anthiinae, comprises about 200 species, occurring mostly in the Indo-West Pacific (Anderson, 2006; Nelson, 2006). Anthiines are often very colourful, but many species are rare and little known, which is probably related to their preference for deeper well structured reef and rocky habitats (Randall \& Heemstra, 2008).

Randall \& Heemstra (2006) erected the genus Meganthias, currently with four recognized species: Meganthias carpenteri Anderson, 2006; M. filiferus Randall \& Heemstra, 2008; $M$. kingyo (Kon, Yoshino \& Sakurai, 2000); and M. natalensis (Fowler, 1925).

Holanthias and Odontanthias appear most similar to the genus Meganthias. Holanthias comprises two species (Randall \& Heemstra, 2006), and Odontanthias 15 (Randall \& Heemstra, 2006; White, 2011; Anderson \& García-Moliner, 2012). Members of both genera differ from Meganthias, amongst other features, mainly in: the near-truncate to rounded caudal fin in Holanthias versus lunulate shape in Meganthias, and the strongly serrate preopercular margin in most Odontanthias versus finely serrate in Meganthias (White, 2011). Further, Meganthias differs in having 8 or 9 anal soft rays versus 7 or 8 (usually 7) in Odontanthias, and the presence of accessory scales on head and body in Meganthias versus the absence of

Corresponding author:

M. Schneider

Email: mschneider@senckenberg.de accessory scales on the body of Odontanthias, although such scales may be present on the head and nape of some species (Randall \& Heemstra, 2006; Anderson \& García-Moliner, 2012).

Meganthias natalensis, now type species of the genus, originally placed in the genus Sacura was described from a single specimen caught off the South African coast of Natal by Fowler (1925). Recently three new species have been described and placed in the genus Meganthias: M. carpenteri based on two specimens caught off Nigeria in the eastern Atlantic (Anderson, 2006); M. filiferus from a single specimen collected in the Andaman Sea off south-western Thailand (Randall \& Heemstra, 2008); and M. kingyo from two specimens from the Ryukyu Islands in the Western Pacific (Kon et al., 2000). Furthermore, Anderson (2006) reported a single specimen of Meganthias sp. of unresolved status from Vema Seamount in the south-eastern Atlantic that exhibits affinities to M. natalensis, but represents most likely a yet undescribed fifth species of the genus (Anderson, 2006).

Meganthias natalensis (Figure 1) is known only from a few specimens caught in the Western Indian Ocean off the coasts of South Africa (from Eastern Cape to KwaZulu-Natal), southern Mozambique, Seychelles and Réunion (Heemstra \& Randall, 1986; Anderson, 2006; Randall \& Heemstra, 2006, 2008).

\section{MATERIALS AND METHODS}

Around noon on 17 February 2012 Michael Janke caught an initially unknown fish of about $400 \mathrm{~mm}$ standard length (SL), while fishing for larger pelagic species in $150 \mathrm{~m}$ depth over a rocky plateau about 10 nautical miles east of Watamu, Kenya (Figure 1). The captain of the fishing boat remembered a similar but much smaller fish being caught 


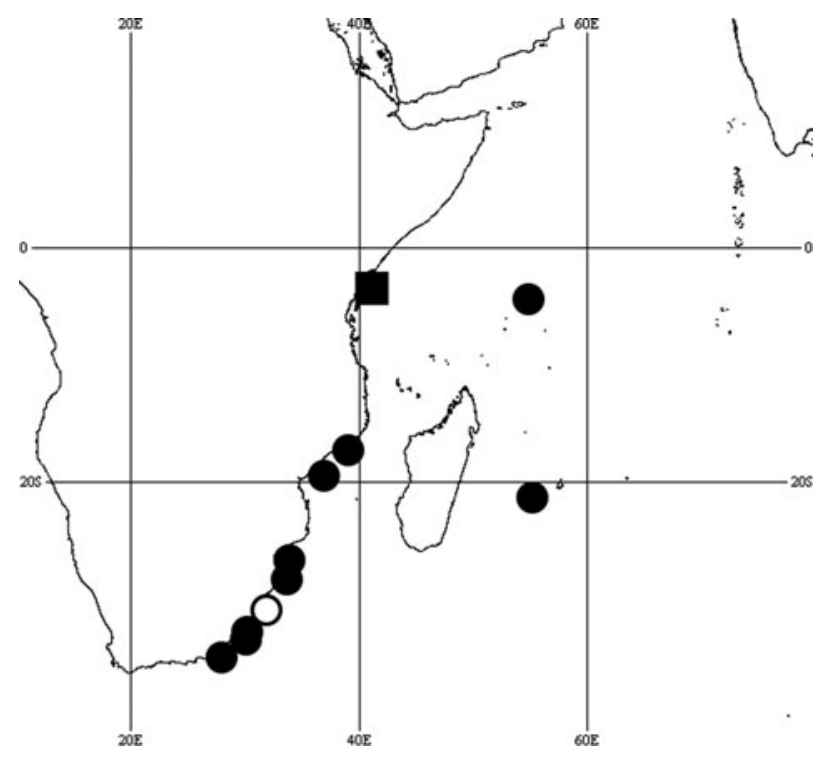

Fig. 1. Distribution of Meganthias natalensis: open circle $(\bigcirc)$ indicates the approximate type locality simply indicated by Fowler (1925: 227) as 'Natal coast'; square ( $\mathbf{\square})$ the new record from Kenya; filled circles ( $)$ indicate records taken from Randall \& Heemstra (2006).

only once during his 30 years of fishing within the region. The specimen reported here was not preserved, but was later sold in the local market. Nonetheless, subsequent analyses of photographs of the fish allow it to be identified as Meganthias natalensis (Fowler 1925).

Though only few photographs of the fresh individual exist (Figures $2 \& 3$ ), they allow examination of diagnostic characters as provided by various authors (Kon et al., 2000; Anderson, 2006; Randall \& Heemstra, 2006, 2008; Akhilesh et al., 2009).

The fishing lure in Figure 2 has a length of $250 \mathrm{~mm}$ and was used as a rough scale. The resulting estimate of the specimen's SL was greater than $400 \mathrm{~mm}$. Meristic and morphometric data were collected following Randall \& Heemstra (2006), except measurement of maxilla width which follows Anderson \& Heemstra (1980). Counts were made on Figures $2 \& 3$, except anal fin ray count which is from Figure 3. Most morphometric data were taken from Figure 3. However, since that photograph was taken from a

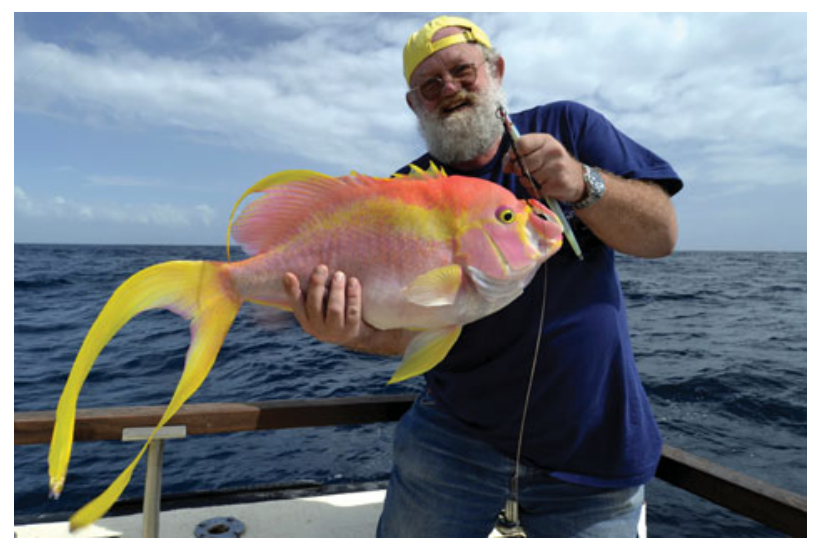

Fig. 2. Meganthias natalensis specimen of $>400 \mathrm{~mm}$ standard length (estimated) immediately after being caught off the Kenyan coast. The pictured fishing lure (jig) equals $250 \mathrm{~mm}$. Photograph: R. Korn.

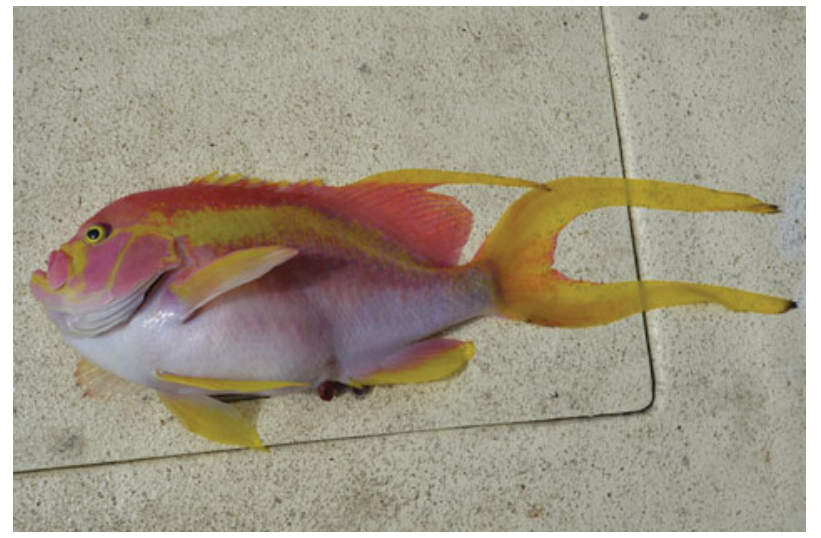

Fig. 3. Same specimen as in Figure 2 of Meganthias natalensis from Kenya stretched on deck. Photograph: R. Korn.

slightly ventral perspective, body depth, depth of caudal peduncle, head length, orbit diameter, maxilla width, predorsal length and dorsal spines were measured on Figure 2. All measurements are estimates at best, since the specimen was not actually examined. Thus, only a limited set of characters has been assessed and compared with published data (Table 1).

\section{RESULTS}

The Kenyan specimen showed the typical characters of Meganthias natalensis as outlined by Randall \& Heemstra (2006): preopercle margin only finely serrate, but no spines or enlarged serrae; middle opercular spine much closer to lower than to upper spine; dorsal profile of head with a convexity centred before upper edge of eye; upper posterior corner of maxilla rounded; lunate-forked caudal fin with slender lobes; caudal fin length 1.4-1.5 times in SL; first to fifth dorsal soft rays prolonged to a pointed lobe; third anal spine clearly longest; and pelvic fins not reaching origin of anal fin. Some meristic and morphometric data are: dorsal fin rays $\sim$ IX, 17; anal rays $\sim$ III, 9; pectoral rays $\sim 16$; pelvic rays $\sim$ I, 5 ; lateral line scales $\sim 43$; head length 3.2 times in SL; orbit diameter 4.7 times in head length; body depth 2.1 times in SL; dorsal spines I $<$ II $<$ III, III - IX subequal, third spine about 3.3 times in HL; first to third dorsal soft rays extremely produced (fourth and fifth rays less so) forming a lobe; longest dorsal soft ray 2.1 times in SL; anal spines I $<$ II $<$ III; caudal fin lobes very elongate; and caudal fin length $\sim 1.5$ times in SL (Table 1).

Since the specimen was photographed immediately after its catch, the extraordinary live coloration is presented in more detail: overall colour pink fading ventrally into white with orchid flush along mid body. Top of head, nape and dorsal profile deep pink. Colour of upper rim of orbit orchid. Upper and lower lips, maxillae, preopercle and opercle fuchsia tinged. Branchiostegal membrane white and the subopercle pink-whitish, its border to preopercle yellow. Spaces surrounding upper and lower lips and maxillae up to the lower rim of orbit yellow. Upper corners of supramaxillae yellow. A yellow line running along the rear edge of preopercle and upper part of opercle, leading into a yellow stripe running from upper rear margin of orbit to upper edge of preopercle. 
Table 1. Meristic and morphometric data for Meganthias natalensis estimated from photographs of the Kenyan specimen and as given by: (1) Randall \& Heemstra (2006) and (2) Anderson (2006), respectively. Counts and measurements were taken from photographs (Figures 2 \& 3) as indicated. Standard length (SL) given in mm. Measurements are given as times in SL and percentages of SL (in parentheses), except for dorsal spines and orbit diameter which are given as times in and as percentage of head length, respectively; $>/<$, minimum/maximum estimates; n.d., no data; $\mathrm{N}$, number of specimens examined.

\begin{tabular}{|c|c|c|c|c|c|}
\hline Character & Kenyan specimen & According to Figures & Comparative material & $\mathbf{N}$ & Source \\
\hline SL & $>400$ & 2 & $174-343$ & 12 & 2 \\
\hline Dorsal fin rays & $\sim \mathrm{IX}, 17$ & $2+3$ & X, 17-19 (rarely 19) & 12 & 1 \\
\hline Anal fin rays & 〜III, 9 & 3 & III, 8-9 (rarely 9) & 10 & 1 \\
\hline Pectoral fin rays & $\sim 16$ & $2+3$ & 16-18 (usually 17 ) & 10 & 1 \\
\hline Ventral fin rays & $\sim \mathrm{I}, 5$ & $2+3$ & $\mathrm{I}, 5$ & 10 & 1 \\
\hline Scales in lateral line & $\sim 43$ & $2+3$ & $43-51$ (usually $45-49$ ) & 12 & 2 \\
\hline Body depth & $2.1(47.1)$ & 2 & $1.95-2.2(45.4-51.3)$ & 10 & 1 \\
\hline Caudal peduncle depth & $8.3(12.1)$ & 2 & $6.9-8.3(12.0-14.5)$ & 12 & 1 \\
\hline Head length & $3.2(31.0)$ & 2 & $2.7-3.1(31.8-37.0)$ & 12 & 2 \\
\hline Orbit diameter & $4.7(21.5)$ & 2 & $3.5-3.75(26.7-28.6)$ & 10 & 1 \\
\hline Maxilla width & $6.1(16.5)$ & 2 & $5.4-7.3(13.7-18.5)$ & 12 & 2 \\
\hline Predorsal length & $3.4(29.3)$ & 3 & $2.8-3.2(31.0-35.3)$ & 12 & 2 \\
\hline Anal fin base length & $5.2(19.4)$ & 3 & $4.7-5.3(18.7-21.3)$ & 12 & 2 \\
\hline Pectoral fin length & $<3.6(>27.8)$ & 3 & $3.1-3.8(26.1-32.3)$ & 12 & 2 \\
\hline Pelvic fin length & $3.0(33.6)$ & 3 & $2.7-3.6(27.5-37.1)$ & 12 & 2 \\
\hline Caudal fin length & $1.5(66.9)$ & 3 & $1.2-2.3(43.5-83.3)$ & 10 & 1 \\
\hline Length of D I & $8.1(12.4)$ & 2 & n.d. & 10 & 1 \\
\hline Length of D II & $4.8(20.9)$ & 2 & n.d. & 10 & 1 \\
\hline Length of D III & $3.8(26.1)$ & 2 & n.d. & 10 & 1 \\
\hline Length of D IV & $3.3(30.3)$ & 2 & $2.6-3.35(29.9-38.5)$ & 10 & 1 \\
\hline Length of D VIII & $4.2(24.0)$ & 2 & n.d. & 10 & 1 \\
\hline Length of longest D soft ray & $2.1(48.5)$ & 3 & $1.9-3.3(29.9-51.9)$ & 12 & 2 \\
\hline Length of longest A soft ray & $4.5(22.4)$ & 3 & $4.1-6.1(16.3-24.0)$ & 12 & 2 \\
\hline
\end{tabular}

A broad yellow band following lateral line, composed of closely set dots above pectoral fins. It starts above opercle, getting more diffuse posteriorly until it narrows below second half of dorsal fin base tapering into upper caudal peduncle by forming diffuse yellow saddle between last five scales in lateral line and caudal peduncle profile. Dorsal fin deep pink with yellow tips on each spine decreasing in size posteriorly from first spine completely yellow to one-third yellow in penultimate spine. Dorsal soft rays distally covered with yellow dots except for last five rays, and upper parts of elongate first to third soft rays all yellow. Anal fin pink fading towards its base. A broad yellow band covering all anal spines distally and most of the length of the first five soft rays, but amount of yellow decreases gradually posteriorly, so that last two anal soft rays all pink. First (upper) ray of pectoral fin tinged fuchsia with lower rays yellow fading into white on lower rays. Outer pelvic rays yellow turning into white on inner rays. Caudal fin all yellow including its base, except some fuchsia rear margin within furcation.

\section{DISCUSSIDN}

Most characters that the photographs allow an acceptable assessment of (Table 1) lie within the range of the Meganthias natalensis material examined by Randall \& Heemstra (2006) and Anderson (2006), who examined beside the material used by Randall \& Heemstra (2006) two additional individuals (cf. Table 1 ). Nevertheless, a disagreement that we found with their data is the dorsal spine count: IX on the Kenyan specimen versus $\mathrm{X}$ in all conspecific material examined by Randall \& Heemstra (2006) and Anderson (2006), and all other members of the genera Meganthias (Kon et al., 2000; Anderson, 2006; Randall \&
Heemstra, 2008; Akhilesh et al., 2009) or Odontanthias (Randall \& Heemstra, 2008). However, this deviation may be inaccuracy due to the difficulty of conducting exact counts on photographs or it just appears as a rare abnormality, but it leaves no doubt about the conspecificity of the specimen with M. natalensis.

Furthermore, the caudal fin lobes of the specimen presented were more rounded than pointed, as described by Randall \& Heemstra (2006) in their key to Meganthias spp., which could have been an artefact due to preservation in specimens they examined.

Depth data, ranging from $88 \mathrm{~m}$ to $183 \mathrm{~m}$, have been reported for four specimens (Randall \& Heemstra, 2006). Thus, these authors presumed that this rare species inhabits deep hard bottoms; furthermore, the contradictory depth of capture of 25 fathoms $(46 \mathrm{~m}$ ) as reported for the holotype, could have been an error. The assumption of Randall \& Heemstra (2006) is supported by the new record from approximately $150 \mathrm{~m}$ depth. Further evidence for a preference of Meganthias inhabiting depths of around $100-200 \mathrm{~m}$ is provided by data available for some congeners: M. filiferus at $150 \mathrm{~m}$ depth (Randall \& Heemstra, 2008); M. kingyo between 100 and $150 \mathrm{~m}$ depth (Kon et al., 2000); whereas for M. carpenteri and Meganthias sp. no data are available (Anderson, 2006).

Randall \& Heemstra (2006) reported a maximum size of $374 \mathrm{~mm}$ SL attained by Meganthias natalensis based on a sample of 12 specimens. The reported maximum size of the four congeners ranges from $278 \mathrm{~mm}$ SL in M. kingyo (Kon et al., 2000), over $293 \mathrm{~mm} \mathrm{SL}$ in M. filiferus (Randall \& Heemstra, 2008; Akhilesh et al., 2009), and $301 \mathrm{~mm} \mathrm{SL}$ in M. carpenteri (Anderson, 2006), to $303 \mathrm{~mm} \mathrm{SL}$ of the yet undescribed species from Vema seamount, south-eastern Atlantic (Anderson, 2006). Thus, the reported specimen of 
M. natalensis of more than $400 \mathrm{~mm}$ SL from Kenya represents the largest individual of the genus Meganthias reported.

Many anthiine species are protogynous hermaphrodites, often exhibiting striking sexual dimorphism in body size and shape, fin length and overall coloration (dichromatism) (Anderson, 2006; Erisman \& Hastings, 2011). This is also true of the members of the genus Meganthias (Kon et al., 2000; Anderson, 2006; Randall \& Heemstra, 2006, 2008). Thus, according to sexed individuals of Meganthias natalensis, as figured by Randall \& Heemstra (2006), the described specimen from Kenya was probably a male. To date there is almost nothing known regarding the biology of Meganthias, consequently, it can only be assumed to be similar to that of other anthiines (Anderson, 2006). In view of the fact, that many anthiine species are only known from the holotype or from very few individuals (Randall \& Heemstra, 2008), it is likely that additional species of Meganthias await discovery.

\section{ACKNDWLEDGEMENTS}

The authors thank A. Malzahn (AWI) who has drawn the attention of the first author (M.S.) to the capture of this unusual fish, R. Korn for taking high-resolution photographs, F. Wicker (SMF) who helped evaluate some critical features of the specimen in the photographs, and K.V. Akhilesh (CMFRI) who promptly provided a reprint.

\section{REFERENCES}

Akhilesh K.V., Pillai N.G.K., Ganga U., Bineesh K.K., Shanis C.P.R. and Manjebrayakath H. (2009) First record of the anthiine fish, Meganthias filiferus (Perciformes: Serranidae) from Indian waters. Marine Biodiversity Records 2, e113, 1-2. DOI: http://dx.doi.org/10. 1017/S1755267209001201.

Anderson W.D. Jr (2006) Meganthias carpenteri, new species of fish from the eastern Atlantic Ocean, with a key to eastern Atlantic Anthiinae (Perciformes: Serranidae). Proceedings of the Biological Society of Washington 119, 404-417.

Anderson W.D. Jr and García-Moliner G. (2012) A new species of Odontanthias Bleeker (Perciformes: Serranidae: Anthiinae) from
Mona Passage off Puerto Rico, the first record of the genus from the Atlantic Ocean. Aqua: International Journal of Ichthyology 18, 25-30.

Anderson W.D. Jr and Heemstra P.C. (1980) Two new species of Western Atlantic Anthias (Pisces: Serranidae), redescription of A. asperilinguis and review of Holanthias martinicensis. Copeia 1980, $72-87$.

Erisman B.E. and Hastings P.A. (2011) Evolutionary transitions in the sexual patterns of fishes: insights from a phylogenetic analysis of the seabasses (Teleostei: Serranidae). Copeia 2011, 357-364.

Fowler H.W. (1925) Fishes from Natal, Zululand and Portuguese East Africa. Proceedings of the Academy of Natural Sciences of Philadelphia 77, 187-268.

Heemstra P.C. and Randall J.E. (1986) Serranidae. In Smith M.M. and Heemstra P.C. (eds) Smiths' sea fishes. Berlin, Heidelberg, New York, London, Paris, Tokyo: Springer, pp. 509-537.

Kon T., Yoshino T. and Sakurai Y. (2000) A new anthiine fish (Perciformes: Serranidae), Holanthias kingyo, from the Ryukyu Islands. Ichthyological Research 47, 75-79.

Nelson J.S. (2006) Fishes of the world. Hoboken, NJ: John Wiley \& Sons, Inc.

Randall J.E. and Heemstra P.C. (2006) Review of the Indo-Pacific fish genus Odontanthias (Serranidae: Anthiinae), with descriptions of two new species and a related new genus. Indo-Pacific Fishes 38, 1-32.

Randall J.E. and Heemstra P.C. (2008) Meganthias filiferus, a new species of anthiine fish (Perciformes: Serranidae), from the Andaman Sea off south-western Thailand. Phuket Marine Biological Center Research Bulletin 68, 5-9.

and

White W.T. (2011) Odontanthias randalli n. sp., a new anthiine fish (Serranidae: Anthiinae) from Indonesia. Zootaxa 3015, 21-28.

\section{Correspondence should be addressed to:}

M. Schneider

HYDRA Institute for Marine Sciences

Elba Field Station

Loc. Fetovaia, Via del Forno 80

I-57034 Campo nell'Elba (LI), Italy

email: mschneider@senckenberg.de 